\title{
EDUCAÇÃO INTEGRAL E ESCOLA DE TEMPO INTEGRAL: mapeamento da produção científica em periódicos (2008 a 2017)
}

\author{
Cristiane Machado' \\ Larissa Barbosa Ferreira²
}

\section{RESUMO}

O objetivo deste artigo é mapear a produção científica sobre educação integral e escola de tempo integral nos artigos científicos de periódicos que constam no Portal de Periódicos Capes, no período de 2008 a 2017. Com base na revisão bibliográfica elaborada por Ribetto e Maurício (2009) que investigou as publicações no período de 1984 a 2007 e constatou aumento das produções científicas em artigos sobre o tema nos últimos anos do espaço temporal estudado, esta investigação indaga: a ampliação das produções sobre educação integral e escola de tempo integral em artigos científicos tem permanecido na última década? Trata-se de uma pesquisa de caráter bibliográfico que se enquadra na metodologia Estado da Arte. A coleta de dados foi feita no Portal de Periódicos da Capes em dois momentos, no primeiro semestre de 2017 foram catalogados os artigos referentes ao período de 2008 a 2016 e, posteriormente, no primeiro semestre de 2018 foram levantadas as informações relativas a 2017 e revisados os dados de 2016. O estudo permitiu concluir que a expansão de publicações em artigos científicos sobre educação integral e escola de tempo integral permanece e de forma crescente ao longo da última década. O período registrou 09 artigos publicados em revistas internacionais, demonstrando um alargamento das fronteiras do debate sobre o tema. As revistas que mais publicaram artigos dentro da temática no espaço temporal da pesquisa são as pertencentes aos estratos Qualis A1 e A2, considerados mais elevados, 71 (53\%) em um total de 135, demonstrando qualidade da produção.

Palavras-chave: Educação integral. Escola em tempo integral. Mapeamento.

\section{INTEGRAL EDUCATION AND SCHOOL OF COMPREHENSIVE TIME: mapping of scientific production in periodicals (2008 to 2017)}

\begin{abstract}
The objective of this article is to map the scientific production on integral education and full-time school in the scientific articles of periodicals that are included in the Capes Periodical Portal, from 2008 to 2017. Based on the bibliographic review

1 Doutora em Educação pela Universidade de São Paulo. Docente do Programa de PósGraduação em Educação da Universidade Estadual de Campinas. E-mail: crimacha@unicamp.br

2 Mestranda em Educação no Programa de Pós-Graduação em Educação da Universidade Estadual de Campinas. E-mail: larissa.fce@gmail.com
\end{abstract}


elaborated by Ribetto and Mauricio (2009) which investigated the publications from 1984 to 2007 and found an increase in scientific productions in articles on the theme in the last years of the studied space, this investigation asks: the amplification of the productions on integral education and full time school in scientific articles has remained in the last decade? It is a bibliographical research that is part of the State of Art methodology. The data collection was done in the Portal of Periodicals of Capes in two moments, in the first semester of 2017 were cataloged the articles referring to the period from 2008 to 2016 and, later, in the first semester of 2018 were collected the information related to 2017 and reviewed the data of 2016. The study allowed to conclude that the expansion of publications in scientific articles on integral education and full-time school has been increasing in the last decade. The period recorded 9 articles published in international journals, demonstrating a widening of the boundaries of the debate on the topic. The journals that published the most articles within the theme in the time frame of the research are those belonging to the Qualis A1 and A2 strata, considered to be the highest, 71 (53\%) out of a total of 135, demonstrating quality of production.

Keywords: Integral education. Full time school. Mapping.

\section{EDUCACIÓN INTEGRAL Y ESCUELA DE TIEMPO INTEGRAL: mapeo de la producción científica en periódicos (2008 a 2017)}

\section{RESUMEN}

El objetivo de este artículo es mapear la producción científica sobre educación integral y escuela de tiempo completo en los artículos científicos de periódicos que constan en el Portal de Periódicos Capes, en el período de 2008 a 2017. Con base en la revisión bibliográfica elaborada por Ribetto y Mauricio (2009) que investigó las publicaciones en el período de 1984 a 2007 y constató aumento de las producciones científicas en artículos sobre el tema en los últimos años del espacio temporal estudiado, esta investigación indaga: la ampliación de las producciones sobre educación integral y escuela de tiempo completo en artículos científicos ha permanecido en la última década? Se trata de una investigación de carácter bibliográfico que se encuadra en la metodología Estado del Arte. La recolección de datos fue hecha en el Portal de Periódicos de la Capes en dos momentos, en el primer semestre de 2017 fueron catalogados los artículos referentes al período de 2008 a 2016 y posteriormente en el primer semestre de 2018 se levantaron las informaciones relativas a 2017 y revisados los datos de 2016. El estudio permitió concluir que la expansión de publicaciones en artículos científicos sobre educación integral y escuela de tiempo completo permanece y de forma creciente a lo largo de la última década. El período registró 09 artículos publicados en revistas internacionales, demostrando una ampliación de las fronteras del debate sobre el tema. Las revistas que más publicaron artículos dentro de la temática en el espacio temporal de la investigación son las pertenecientes a los estratos Qualis A1 y A2, considerados más elevados, 71 (53\%) en un total de 135, demostrando calidad de la producción.

Palabras clave: Educación integral. Escuela a tiempo completo. Mapeo. 


\section{INTRODUÇÃO}

Este artigo tem por objetivo apresentar o mapeamento da produção sobre educação integral e escola em tempo integral em artigos de periódicos científicos que constam no Portal de Periódicos da Coordenação de Aperfeiçoamento de Pessoal de Nível Superior (Capes), no período de 2008 a 2017.

O propósito é atualizar dados e informações sobre a produção científica em artigos relativa à última década, semelhante ao que foi feito por Ribetto e Maurício (2009) com foco no período de 1984 a 2007. Essa pesquisa, que "mapeou a produção sobre o tema em revistas, livros, dissertações e teses" (RIBETTO; MAURíCIO, 2009, p. 137), detectou, dentre outros achados, 55 artigos veiculados durante os 23 anos investigados, com grande concentração das publicações nos últimos cinco anos do espaço temporal estudado, evidenciando que "a discussão sobre educação em tempo integral vem se ampliando" (RIBETTO; MAURíCIO, 2009, p. 145). A constatação das autoras nos instigou questionar: a ampliação das produções sobre educação integral e escola em tempo integral em artigos científicos tem permanecido na última década?

A escolha em mapear a produção em artigos se deu pelo reconhecimento de que "o periódico científico constitui o principal veículo de transferência da informação científica e tecnológica, sendo uma relevante fonte de informação para a pesquisa" (MEIRELLES; MACHADO, 2007, p. 55). A produção científica tem centralidade na ciência e é por meio da divulgação do que é produzido cientificamente que a ciência é conhecida e, eventualmente, praticada. Neste sentido, "a produção científica disseminada em periódicos científicos é de suma importância para o se fazer ciência no âmbito acadêmico" (SILVEIRA, 2012, p. 116).

Concorreu, também, para despertar interesse por este estudo a divulgação, pelo Instituto Nacional de Estudos e Pesquisas Anísio Teixeira INEP (BRASIL, 2017), de dados sobre as matrículas em tempo integral no ensino fundamental. De acordo com este Instituto, de 2010 a 2015 o número de matriculados mais que triplicou no período, passou de 1.327.129 para 
4.648.277 de estudantes, indicando possível reflexo no alargamento estudos e pesquisas sobre a temática e, consequentemente, nas produções científicas.

A pesquisa é de caráter bibliográfico e se enquadra na metodologia Estado da Arte, também conhecida pelas formas correlatas Estado do Conhecimento e Estado da Questão, entretanto, segundo Puentes, Aquino e Faquin (2005) a expressão Estado da Arte é a mais utilizada em investigações pautadas em revisões bibliográficas. Messina (1998) explica que estudos que focam essa metodologia têm o potencial de contribuir com a teoria e a prática de uma determinada área do conhecimento, ressalta, ainda, que "um estado da arte é um mapa que nos permite continuar caminhando" (MESSINA, 1998, p. 01). Romanowski e Ens (2006, p. 39) afirmam que "a realização destes balanços possibilita contribuir com a organização e análise na definição de um campo, uma área, além de indicar possíveis contribuições da pesquisa para com as rupturas sociais".

A coleta de dados foi feita no Portal de Periódicos da Capes em dois momentos. Inicialmente, durante o primeiro semestre de 2017, foram catalogados os artigos referentes ao período de 2008 a $2016^{3}$ e, posteriormente, no primeiro semestre de 2018 foram levantadas as informações relativas a 2017. Cabe esclarecer que, nesta segunda fase, os dados de 2016 foram revisados e complementados, tendo em vista a permanente instabilidade da plataforma por ocasião do primeiro momento de levantamento das informações.

Com o objetivo de atingir um maior número possível de artigos foram utilizados seis descritores combinando palavras-chave com estreita relação com os temas do estudo: educação integral; educação de tempo integral; educação em tempo integral; escola integral; escola de tempo integral; escola em tempo integral. A pesquisa foi feita com o uso do filtro 'artigo' da

\footnotetext{
3 O levantamento inicial deste estudo, realizado em 2017 referente ao período de 2008 a 2016, foi feito por Telma Cristina do Nascimento em pesquisa de Iniciação Científica no âmbito do Programa Nacional de Cooperação Acadêmica - PROCAD. Em 2018, os dados foram revistos, ampliados e complementados por Larissa Barbosa Ferreira, Mestranda na Faculdade de Educação da Universidade Estadual de Campinas.
} 
plataforma e localizou 210 artigos no total, destes foram desprezados títulos repetidos e os trabalhos que não faziam interface com a área da educação, restando 135 artigos que compuseram a amostra investigada.

Os títulos foram registrados em uma planilha Excel com as seguintes informações em colunas verticais: nome do/s autor/es; origem geográfica da revista; título do artigo, ano de publicação; nome do periódico; número da revista; Qualis do periódico; palavras-chave e resumo. Ainda, com base na leitura dos resumos, foi elaborada a classificação dos artigos por tipo de pesquisa empreendida para a produção do trabalho, se estudo teórico, de cunho ensaístico, ou investigação também empírica, com a incorporação de pesquisa de campo. Por fim, os artigos foram baixados integralmente dos sites das revistas e arquivados em uma pasta virtual.

\section{EDUCAÇÃO INTEGRAL E ESCOLA EM TEMPO INTEGRAL: apontamentos de políticas e legislação}

A origem da implementação de iniciativas de educação integral e de escola de tempo integral no Brasil tem no educador Anísio Teixeira sua principal referência e inspiração. Influenciado pelo pensamento educacional de John Dewey, de quem foi aluno na Universidade de Columbia, em Nova Iorque, disseminou os ideais da "Escola Nova" em contraposição à "Escola Clássica", defendendo uma educação que considerasse o processo educativo a própria vida e não como preparação para a vida e uma escola que se aproximasse da realidade social dos alunos.

Com o objetivo de materializar a filosofia da Escola Nova, Anísio Teixeira idealizou e construiu o Centro Educacional Carneiro Ribeiro (CECR), em 1952, em Salvador (BA), com a intenção de instalar um espaço educacional que alternasse atividades intelectuais e práticas durante de todo o dia, composto por "Escolas-Classe" e "Escola-Parque".

A experiência do CECR, pelo seu pioneirismo, se constituiu um marco e uma referência para a implantação de outras que se seguiram. Quando foi diretor do INEP (Instituto Nacional de Estudos Pedagógicos) em Brasília, na 
década de 1960, o educador Anísio Teixeira propôs a construção de 28 "Escolas-Parque", porém só algumas foram efetivadas. Para ele, a ideia de educação integral estava atrelada à ampliação do tempo de permanência na escola e deveria ter como princípio a formação integral da criança, portanto, era necessário romper com os modelos tradicionais que fundamentavam as práticas educativas e criar uma escola que pudesse acolher a ensinar seus alunos em tempo integral (TEIXEIRA, 1962).

A fecunda contribuição de Anísio Teixeira para a implantação de políticas de ampliação da permanência dos estudantes na escola foi inestimátivel, conforme Cavaliere (2010, p. 259):

\begin{abstract}
A forma como o autor concebeu a educação integral e a escola de tempo integral é fonte imprescindível para uma abordagem do tema que se mantenha orientada pelo sentido de democratização da realidade educacional brasileira.
\end{abstract}

Silva (2018), em tese de doutoramento sobre o tema, corrobora a afirmação de Cavaliere (2010) ao asseverar que:

Após realização de pesquisas, tanto em sua obra, quanto em livros e textos que foram escritos sobre ele e, por fim, em trabalhos acadêmicos sobre educação integral, em todos encontramos subsídios que nos permitem concluir que Anísio Teixeira é o maior idealizador e, portanto, a maior referência na luta por uma educação pública de qualidade, igualitária, laica, de dia inteiro, que vise a formação plena de nossas crianças e jovens (SILVA, 2081, p. 74).

A partir dessa experiência, com inspiração nos pressupostos de Anísio Teixeira, várias políticas educação integral e escola em tempo integral foram implementadas em diferentes contextos e momentos históricos no país.

Algumas iniciativas representam importantes marcos nas políticas de educação integral, como a criação dos Centros Integrados de Educação Pública (CIEPs), idealizados por Darcy Ribeiro durante os governos de Leonel Brizola em meados da década de 1980. A implantação desta experiência estava pautada na perspectiva de educação integral em dois sentidos: educar o estudante em todas as suas dimensões e ampliar o tempo de 
permanência na escola para 8 horas diárias. Faria (1991, p. 14) explica a amplitude e a importância desta empreitada:

(...) Os CIEPs tinham objetivos mais abrangentes do que aqueles das escolas tradicionais de $1^{\circ}$ grau. Além das atividades específicas inerentes a este grau de ensino, os CIEPs teriam funções mais amplas, como centro comunitário de educação, de cultura e de lazer. Atenderiam, através do programa de Educação Juvenil, no horário noturno, os jovens entre 14 e 20 anos que não receberam escolaridade de $1^{\circ}$ grau na idade própria; atenderiam a grupos de alunos de 7 a 14 anos residentes nos CIEPs (Projeto AlunosResidentes), a fim de suprir a ausência de pais ou responsáveis; e constituiriam centros de cultura e lazer abertos também à comunidade em que estivessem inseridos.

Em 1990, no governo Collor, foram criados os Centros Integrados de Atendimento à Criança (CIACs), renomeados por Itamar Franco como Centro de Atenção Integral à Criança (CAICs), após o impeachment de Collor. Foram construídas 200 unidades em várias cidades, apesar da promessa de chegar a cinco mil equipamentos. O objetivo era ampliar o tempo de permanência dos estudantes na escola, ofercendo uma educação em tempo escolar integral. Como a implementação dependia de assinatura de convênio entre municípios e governo federal, o projeto, de acordo com Gadotti (2009, p. 27),

(...) foi criticado por muitos educadores que o consideraram apenas um projeto "promocional" e não pedagógico, acreditando que a distribuição dessas cinco mil novas unidades escolares, pelos Estados e municípios, obedeceria apenas a interesses políticos.

Já nos anos 2000, em São Paulo, foram implantados os Centros Educacionais Unificados (CEUs), na gestão da prefeita Marta Suplicy, a partir de uma ideia originada no governo municipal de Luiza Erundina, em 1992. O projeto, ainda em funcionamento com cerca de 120 mil estudantes distribuídos em 46 CEUs, foi concebido como uma proposta intersetorial fundamentanda no princípio de atuar, de forma articulada, em diversas áreas: meio ambiente, educação, emprego e renda, participação popular, desenvolvimento local, saúde, cultura, esporte e lazer. Neste sentido, 
Os Ceus inspiram-se na concepção de equipamento urbano agregador da comunidade, com uma visão de educação que transcende a sala de aula e o espaço escolar. Os Ceus constituemse em centros de experimentação educacional e de investigação, começando pelo mapeamento da realidade local, das condições socioculturais, econômicas, geográficas, históricas (GADOTTI, 2009, p. 29).

De acordo com Hayashi e Kerbauy (2016, p. 841):

Todas essas experiências nos conduzem até os dias de hoje, com o Projeto Mais Educação, que teve início durante o governo Lula (20032010) e persiste durante os mandatos de Dilma Rousseff (2011 até a atualidade). A estratégia desses governos foi induzir a ampliação do tempo, dos espaços e das oportunidades educativas, na perspectiva da Educação Integral com o objetivo de melhorar a Educação no país tendo como prioridade a Educação Básica.

O Programa Mais Educação foi instituído em 2007, por meio da Portaria Interministerial $n^{\circ} 17 / 2007$ (BRASIL, 2007), para estimular a jornada integral nas escolas. Para Moll e Leclerc (2013, p. 293) a iniciativa é um:

(...) marco setorial de referência, como amálgama de forças que configuram o campo emergente de educação integral em tempo integral. [...] Essa estratégia desencadeou processos inéditos, em termos de escala nacional, em parceria com os sistemas de ensino, almejando exercer papel coadjuvante.

Paralelamente, a legislação educacional também avançou na tentativa de estimular políticas de educação integral. Dentre outras, pode-se destacar a Lei de Diretrizes e Bases da Educação Nacional (Lei Federal 9394/1996) que normatizou o oferecimento progressivo de jornada escolar ampliada no ensino fundamental no artigo 34 e o Plano Nacional de Educação (2014/2024), aprovado por meio da Lei n 13.005, em 25 de junho de 2014, que colocou a ampliação do tempo de permanência na escola como uma das 20 principais metas para a educação no país, prevendo a oferta de educação em tempo integral para no mínimo $50 \%$ das escolas públicas e o atendimento de ao menos $25 \%$ dos estudantes de educação básica. 
Esses apontamentos sinalizam para um crescente fortalecimento, lento, mas constante, de políticas de implementação de educação integral e escola de tempo integral no país, apoiado, de um lado, por iniciativas governamentais e, por outro, pela legislação educacional.

\section{EDUCAÇÃo INTEGRAL E ESCOLA DE TEMPO INTEGRAL NOS PERIÓDICOS: mapeamento de 2008 a 2017}

Este levantamento compõe o espectro de pesquisas que adotam a metodologia Estado da Arte. São estudos que têm o propósito de "mapear e discutir certa produção acadêmica em determinado campo do conhecimento" (FERREIRA, 2002, p. 258), de caráter bibliográfico, em geral, visam inventariar e sistematizar a produção da área escolhida. A principal finalidade destes estudos é a "identificação, registro [e] categorização que levem à reflexão e síntese sobre a produção científica (SOARES, 2000, p. 155)".

A revisão bibliográfica é a sustentação da pesquisa científica e uma das partes mais significativas do processo de elaboração de trabalhos acadêmicos. É o recenseamento do tema investigado que possibilita conhecer o estado do conhecimento sobre determinados temas e assuntos, suas lacunas e seus avanços.

A base de dados escolhida para este estudo foi o Portal de Periódicos da Capes. Existente desde o ano de 2000, a plataforma "tem como missão promover o fortalecimento dos programas de pós-graduação no Brasil por meio da democratização do acesso online à informação científica internacional de alto nível" (BRASIL, 2018).

O levantamento dos artigos, efetuado no primeiro semestre de 2017 , referente aos anos de 2008 a 2016 e revisto e complementado no primeiro semestre de 2018 incluindo artigos de 2017, localizou 135 títulos. Para este mapeamento, os artigos foram classificados de acordo com: quantidade de artigo publicado em cada periódico; localização geográfica (país ou estado brasileiro) da revista que publicou o artigo; porcentagem de publicação por origem; distribuição das publicações por ano e país; origem dos periódicos 
conforme regiões brasileiras; distribuição das publicações por ano da amostra estudada, de 2008 a 2017 e Qualis da revista, conforme avaliação do quadriênio 2013-2016. Ainda, a partir da leitura dos resumos dos artigos, foi mapeado o tipo de pesquisa que fundamentou o artigo; o cruzamento do tipo de pesquisa com o Qualis do periódico e o cruzamento do tipo de pesquisa e com o ano de publicação.

Os 135 artigos da amostra foram publicados em 65 diferentes periódicos, evidenciando ampla circulação da produção científica no escopo da temática, sendo que o veículo que mais divulgou artigo com o tema da educação integral e da escola em tempo integral publicou 11 artigos e os que menos publicaram figuram com um artigo cada, totalizando 38 revistas nesta categoria. O Gráfico 1 demonstra tal distribuição:

Gráfico 1: Quantidade de artigo publicado por periódico

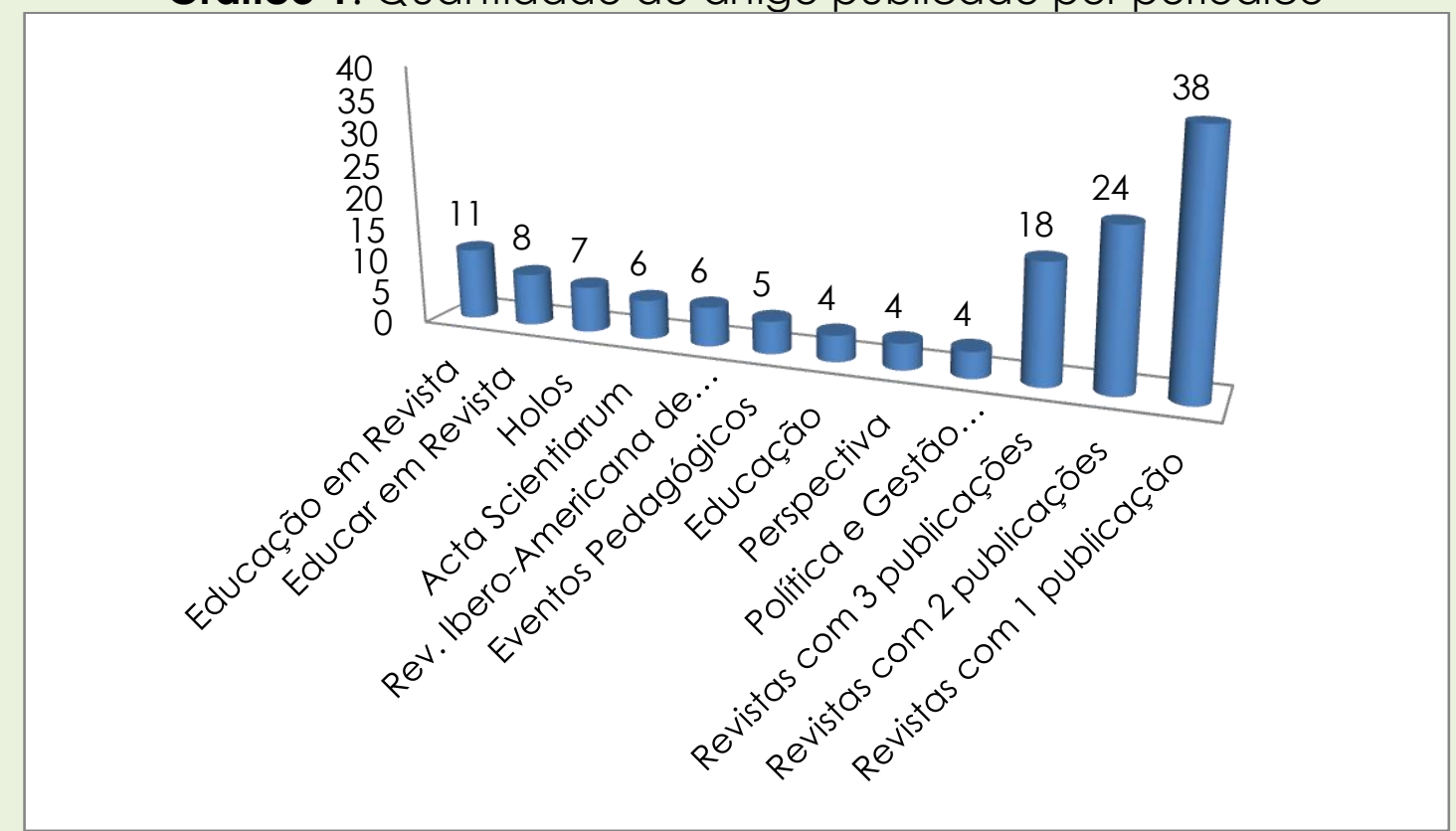

Fonte: As autoras com base no Portal Capes.

A classificação dos 135 artigos por ano de publicação demonstra um aumento considerável na produção de artigos científicos, especialmente, nos últimos três anos (2015-2017), com ligeira queda em 2017 em relação aos dois anteriores. É o que se nota no Gráfico 2: 
Gráfico 2: Classificação das publicações por ano:

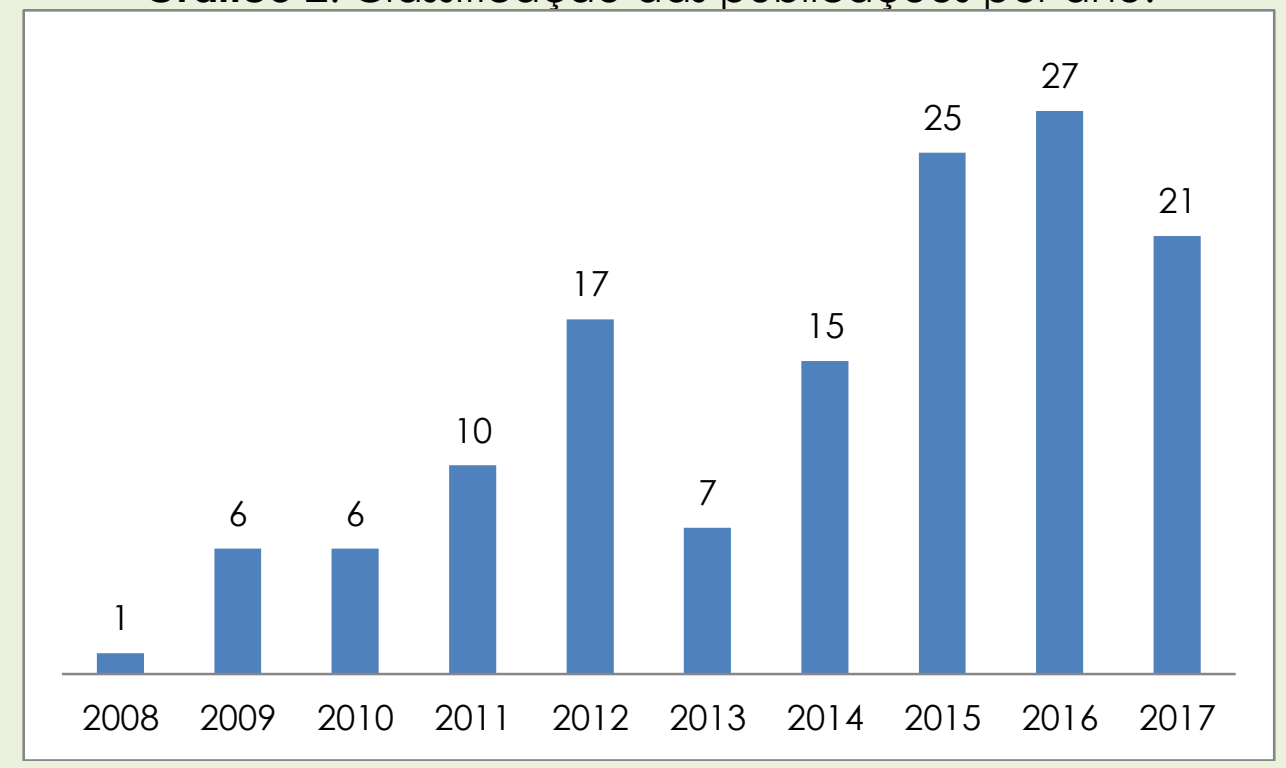

Fonte: As autoras com base no Portal Capes.

Observando as publicações em todos os anos da amostra pesquisa, de 2008 a 2017, é possível perceber, ainda que com oscilações para mais e para menos, o aumento da produção de artigos com a temática da investigação é constante. É visível que, a partir de 2010, a ampliação da produção sobre o tema é mais acentuada e permanece contínua até 2017 , exceto em 2013 e 2014.

Este movimento de crescimento no interesse em produzir e divulgar estudos com o tema educação integral e escola em tempo integral, ao que parece, se coaduna com a expansão do atendimento de estudantes em período integral no ensino fundamental. Como dito anteriormente, dados do INEP (BRASIL, 2017) demonstram que, de 2010 a 2015, essas matrículas passaram de 1.327.129 para 4.648.277 de estudantes.

Os periódicos nos quais os artigos foram publicados são, na sua maioria, editados no Brasil, entretanto, é possível verificar outros países que também divulgaram artigos brasileiros sobre a temática, como Colômbia, Costa Rica, Espanha, Estados Unidos e Portugal. O Gráfico 3 apresenta a distribuição da origem geográfica dos periódicos que publicaram artigos sobre educação integral e escola em tempo integral entre 2008 e 2017: 
Gráfico 3: Origem geográfica dos periódicos:

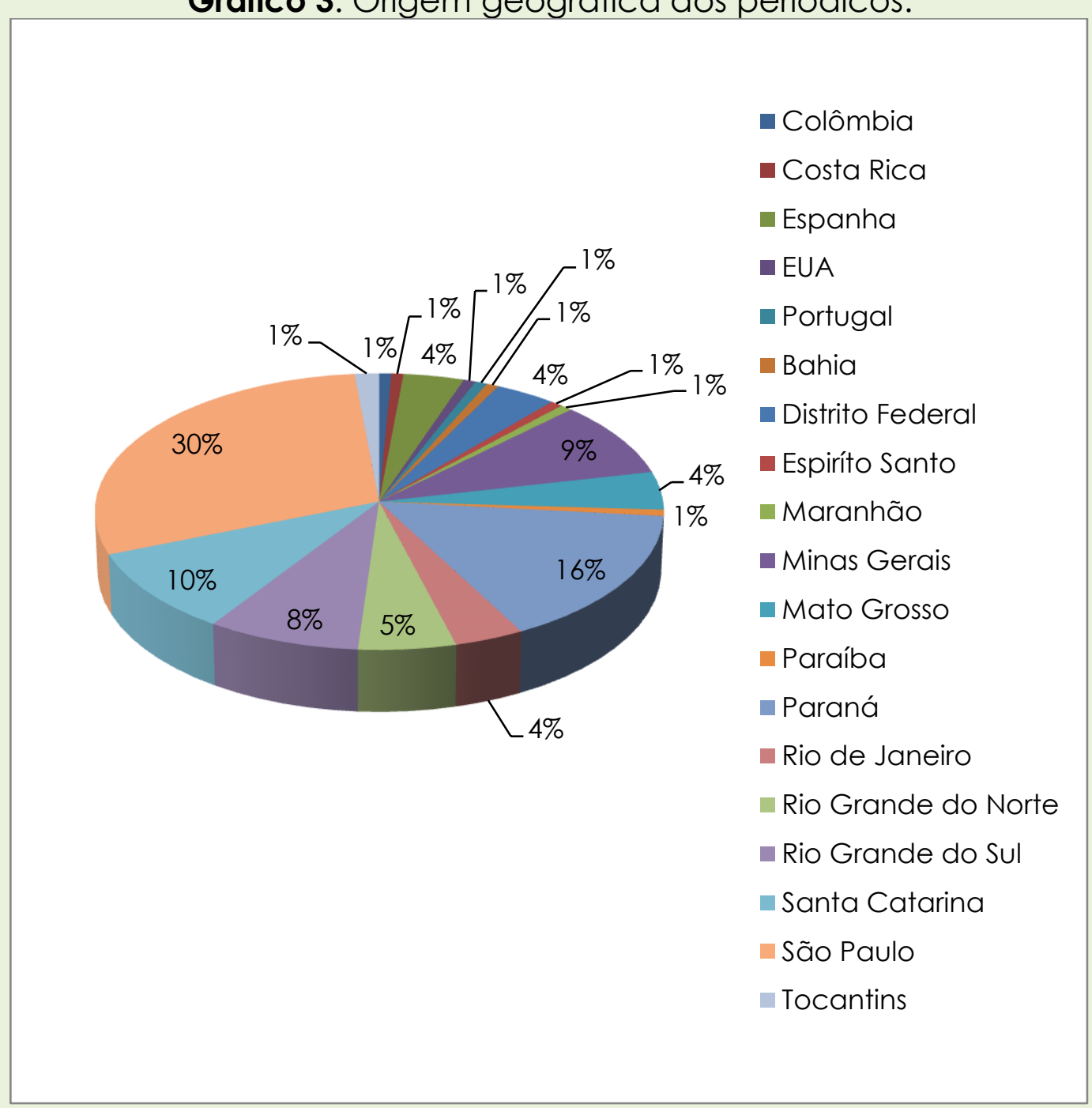

Fonte: As autoras com base no Portal Capes.

Esses dados demonstram que a circulação do conhecimento produzido sobre o tema da educação integral e da escola de tempo integral tem atendido à tônica da internacionalização da produção científica, fomentada pelos órgãos reguladores do ensino superior e da pósgraduação no Brasil, segundo Ramos $(2018$, p. 01) "nas últimas duas ou três décadas, a dimensão internacional tornou-se parte integral da educação de nível superior e da pesquisa científica".

As revistas internacionais somam nove artigos publicados, o que representa $8 \%$ do total da amostra de 135 artigos, sendo que na Espanha foram publicados cinco títulos e nos demais países um trabalho científico em cada periódico, conforme Gráfico 4. 
Gráfico 4: País de origem dos periódicos

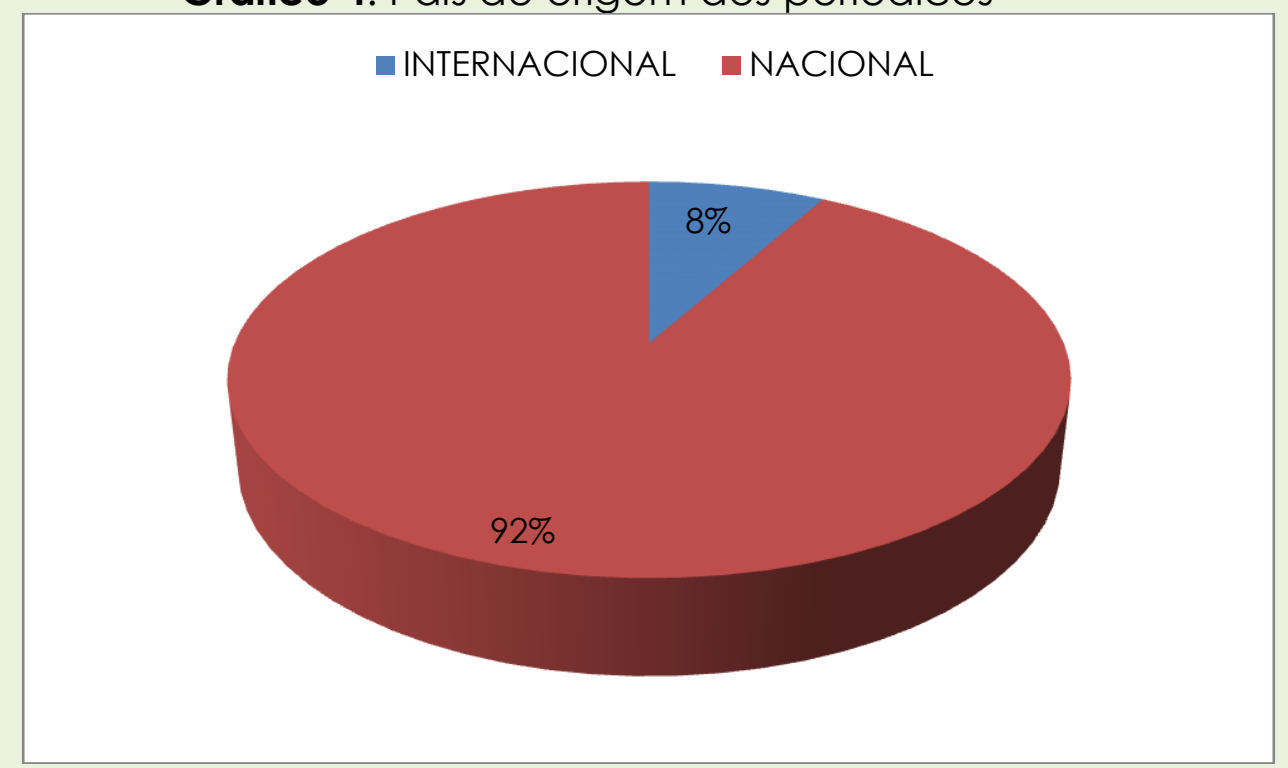

Fonte: As autoras com base no Portal Capes.

O cruzamento das informações sobre o ano da publicação e a origem dos periódicos indica que o interesse destas revistas no tema e a iniciativa dos pesquisadores em submeter trabalhos em revistas internacionais são relativamente recentes, uma vez que grande parte das publicações, oito do total de nove, foram efetivadas entre 2011 e 2016.

Esses dados reiteram que a participação do país na internacionalização do conhecimento produzido ainda é tímida, de acordo com Ramos (2018, p. 03), "entre 2007 e 2011, o Brasil contribuiu com 2,59\% (147.503 artigos científicos) do total mundial, número que coloca o país na $13^{a}$ posição do ranking global", entretanto, há que se salientar a tendência de crescimento quando observados os anos das publicações, conforme Gráfico 5. 
Gráfico 5: Ano e país de publicação dos artigos

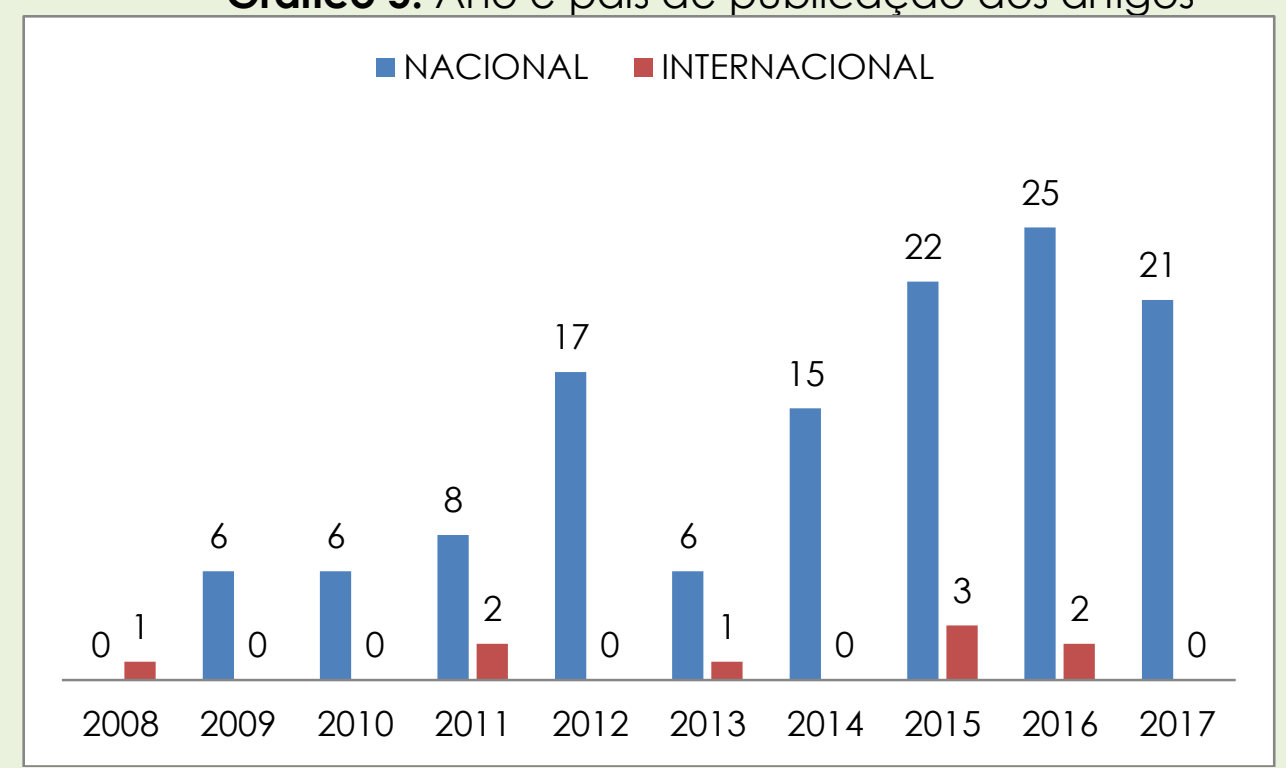

Fonte: As autoras com base no Portal Capes.

A compilação da origem geográfica dos 126 artigos publicados em revistas nacionais, extraindo da amostra de 135 os nove publicados em periódicos internacionais, revelam que a região sudeste concentra maior parte dos veículos que compõe a amostra, $46 \%$ do total, seguida da região sul do país, com 36\%. O Gráfico 6 registra tais informações:

Gráfico 6: Distribuição dos periódicos por região brasileira:

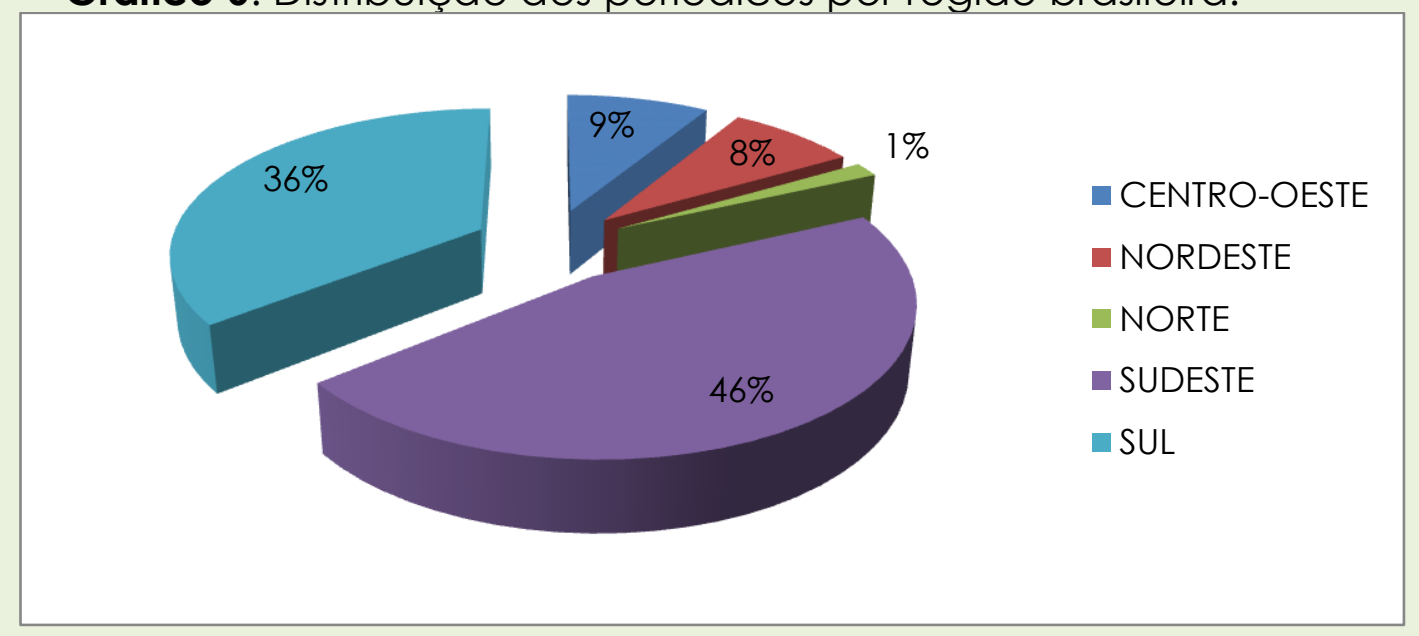

Fonte: As autoras com base no Portal Capes.

Pesquisas desenvolvidas alhures corroboram estes dados. Podemos citar duas investigações como ilustrativas. 
Estudo de Hayashi e Kerbauy (2016) que sistematizou a produção acadêmica em teses e dissertações sobre educação integral no período de 2010 a 2015 corrobora essa constatação. Os autores verificaram que os programas de pós-graduação da região sudeste condensam grande parte das pesquisas estudadas, uma vez que "a maioria dos programas de pósgraduação da área de Educação no país está localizada nessa região" (HAYASHI; KERBAUY, 2016, p. 847).

O MEC (BRASIL, 2009), em 2008, elaborou uma pesquisa por meio de questionário, para mapear as experiências municipais de ampliação de jornada na escola dos estudantes e verificou que, do total de 2.112 municípios que responderam à pesquisa, aqueles que ficam nas regiões sudeste e sul se destacam como os que mais desenvolvem políticas de educação integral e escola em tempo integral, $37 \%$ e $25 \%$ respectivamente, do total de cidades que responderam ao instrumento enviado.

Este estudo sistematizou, também, as publicações de acordo com o Qualis do periódico publicado. Conforme o site da Capes, O "QualisPeriódicos é um sistema utilizado pela Capes para classificar a produção científica dos programas de pós-graduação, no que se refere aos artigos publicados em periódicos científicos" (BRASIL, 2018).

A classificação, feita por um Comitê de Consultores para cada área de avaliação de acordo com critérios estabelecidos pelo Conselho TécnicoCientífico da Educação Superior (CTC/ES), tem o objetivo de refletir a importância relativa dos diferentes periódicos para uma determinada área. Os periódicos são enquadrados em estratos indicativos de qualidade, sendo O A1 mais elevado seguido de A2, B1, B2, B3, B4, B5 e C, este útlimo com peso zero. De acordo com Morosini (2015, p. 104), são critérios para avaliação, dentre outros, reconhecimento na área; caráter acadêmico-científico; amplitude de circulação; periodicidade e regularidade; diversidade nacional e institucional do conselho editorial e corpo de pareceristas; número de artigos por ano; diversidade institucional dos autores publicados; indexação em bases de dados nacionais e internacionais. 
A distribuição dos 135 artigos levantados na coleta de acordo com o Qualis do periódico publicado revelou que mais da metade deles, 53\%, que representa 71 artigos, foi publicada em revistas com os Qualis mais elevados, A1 ou A2. No primeiro estrato foram publicados 35 artigos, $26 \%$ do total, e no segundo 36, representando $27 \%$ da amostra. Nos outros estratos, as publicações foram assim distribuídas: B1: 23 (17\%); B2: 24 (18\%); B3: 5 (4\%); B4: 2 (1\%); B5: 9 (6\%); C:1 (1\%). O Gráfico 7 demonstra em porcentagem os dados:

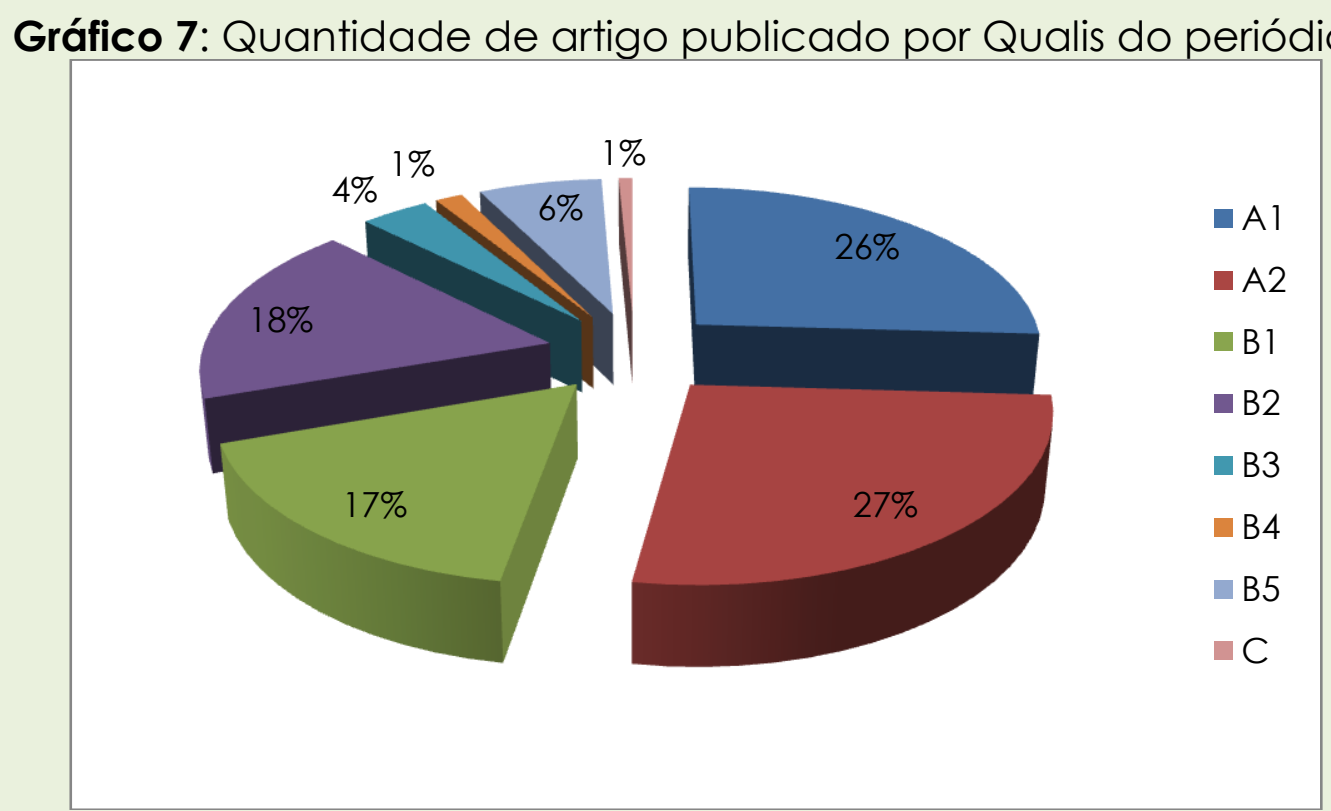

Fonte: As autoras com base no Portal Capes.

O cenário obtido com a sistematização dessa informação permite asseverar que são artigos, na sua maioria, considerados de qualidade científica, uma vez que foram publicados em periódicos com as melhores pontuações na classificação divulgada pelo Qualis-Periódicos da Capes.

Os dados também possibilitam visualizar que, exceto as publicações nas revistas do estrato B5, quanto menor a classificação do periódico, menor é o número de artigos publicados, reforçando a afirmação de que os títulos dentro da temática analisada possuem reconhecida qualidade pela comunidade acadêmica e são publicados, prioritariamente, nas revistas científicas com mais alta classificação. 
Assim, pode-se afiançar que, o tema dessa investigação, educação integral e escola de tempo integral, tem mobilizado pesquisadores no desenvolvimento de investigações acadêmicas por se tratar de temas relevantes tanto para as instituições de ensino superior como também, para a sociedade. Consoante assertiva de Morosini (2015, p. 102):

(...) a construção de uma produção científica está relacionada não só à pessoa/pesquisador que a produz, mas a influências da instituição na qual está inserida, do país em que vive e de suas relações com a perspectiva global.

A sistematização dos títulos por tipo de pesquisa empreendida para subsidiar a elaboração dos artigos foi efetuada para permitir futuras explorações na revisão bibliográfica. A partir da leitura dos resumos dos 135 artigos selecionados, o contingente da amostra foi separado em artigo tipo ensaio, que consiste em uma "exposição lógica e reflexiva e em argumentação rigorosa com alto nível de interpretação e julgamento pessoal" (SEVERINO, 1996, p. 120); e artigos que utilizaram a pesquisa empírica como forma de abordagem do tema educação integral e escola em tempo integral.

O Gráfico 8 é representativo do encontrado na sistematização por tipo de pesquisa que fundamentou o artigo. Constatou-se que 74 artigos, ou seja, $55 \%$ do total versavam sobre as teorias envolvidas na temática, ou seja, de cunho ensaístico, os demais, 61 títulos, ou seja, 45\% da amostra lançaram mão da empiria para o desenvolvimento da investigação, ou seja, além do debate teórico, foram a campo para auscultar as experiências de ampliação do tempo de permanência do estudante na escola. 
Gráfico 8: Tipo de pesquisa que fundamentou o artigo:

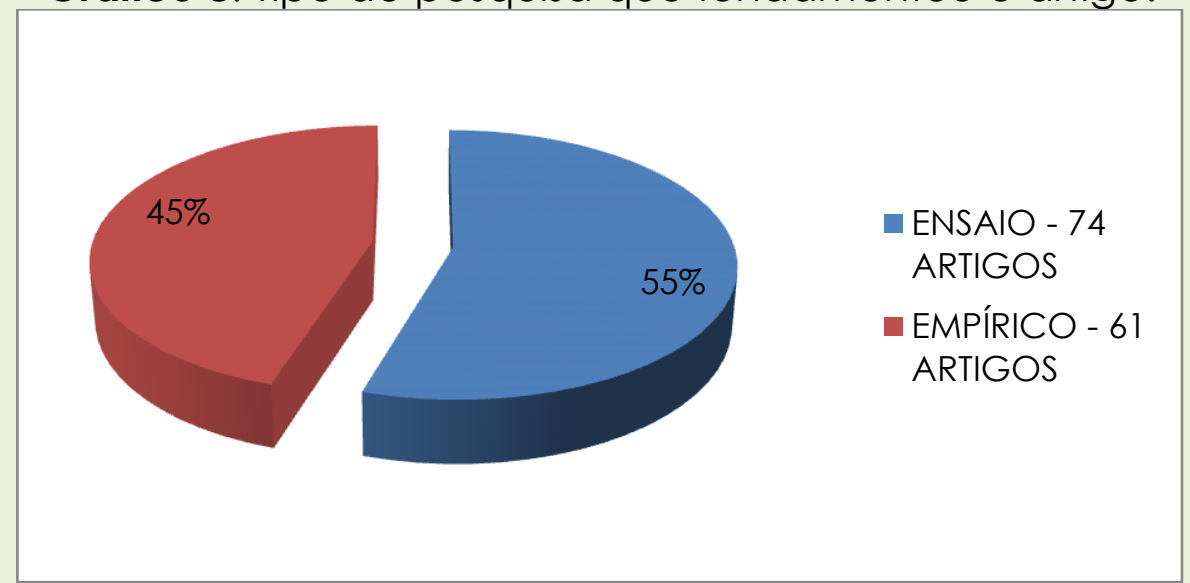

Fonte: As autoras com base no Portal Capes.

É possível afirmar, portanto, que 74 artigos sustentam 0 debate proposto em argumentos teóricos e 61 títulos buscam elementos na pesquisa de campo para fortalecer e respaldar a discussão entabulada. Sabe-se que toda pesquisa necessita de referenciais teóricos, mas nem toda pesquisa adentra em metodologias empíricas para evidenciar elementos das experiências com educação integral e escola de tempo integral, neste levantamento, $45 \%$ dos títulos pesquisados utilizaram o recurso da empiria.

Alguns resumos dos artigos que compuseram a amostra desta revisão bibliográfica exemplificam os tipos de pesquisas desenvolvidas para respaldar o debate apresentado.

Em "As artes na educação integral: uma apreciação histórico-crítica", artigo de cunho ensaístico, Ferreira e Duarte (2011, p. 115) teceram reflexões sobre o papel da arte no conteúdo escolar da educação integral, buscando compreender a colaboração da arte para o desenvolvimento humano com o objetivo de "contribuir com a defesa da necessidade de uma educação integral na qual a arte [...] se oponha ao caráter predominante fetichista e unilateral das atividades que constituem a vida na sociedade capitalista contemporânea". De acordo com os autores, para atingir este propósito:

(...) Os argumentos desenvolvidos no artigo fundamentam-se em estudos sobre a arte realizados por Lev Vigotski e por Georg Lukács, bem como em estudos educacionais realizados por Dermeval Saviani (FERREIRA; DUARTE, 2011, p. 115). 
Também apoiados em estudo ensaístico, Silva e Silva (2013, p. 701), no artigo "A hegemonia às avessas no Programa Mais Educação", tiveram o objetivo de analisar a concepção de educação integral do Programa Mais Educação e, para tanto, basearam-se na análise documental para concluir que o programa estava pautado em "uma concepção intercultural, assentada numa gestão intersetorial e sistêmica, instrumentos de democratização e inovação capazes de melhorar a qualidade da educação".

O artigo de Hayashi e Kerbauy (2016, p. 836) teve o objetivo de mapear a produção acadêmica em teses e dissertações acerca do tema educação integral no período de 2010 a 2015. Para tanto, utilizou-se de estudo teórico para traçar "um panorama histórico do ideário de educação integral e das políticas públicas que adotaram essa perspectiva e analisa a produção científica sobre essa temática desenvolvida em programas de pós-graduação de educação do país".

O artigo "A escola de tempo integral: desafios e possibilidades" de Castro e Lopes (2011) é um estudo de caso e pode ser compreendido como um dos exemplos de trabalhos fundamentados na pesquisa empírica. As autoras analisaram a

(...) correlação entre os objetivos arrolados pela política educacional e os dados da experiência concreta, a fim de compreender os avanços, desafios e limites da proposição de uma educação pública de melhor qualidade, a partir da Escola de Tempo Integral (CASTRO; LOPES 2011 , p. 259).

Felício (2011) também empreendeu estudo com pesquisa de campo, de cunho empírico, com o propósito de investigar a construção do currículo de uma escola de tempo integral. No artigo publicado "A instituição formal e a não formal na construção do currículo de uma escola de tempo integral", a autora declara que partiu de "uma perspectiva qualitativa, compreendendo observação, análise documental e entrevistas com os educadores das duas instituições" (FELíCIO, 2011, p. 163). 
A pesquisa de Ferreira e Rees (2015), "Educação integral e Escola de tempo integral em Goiânia", investigou as concepções dos integrantes do corpo docente e administrativo de uma escola pública do município de Goiânia sobre educação integral e tempo integral. De acordo com as autoras, para o estudo qualitativo de cunho etnográfico:

(...) foram utilizados os seguintes instrumentos de geração de dados: observação-participante, entrevistas, anotações de campo e leitura dos documentos oficiais que legislam sobre a educação integral e tempo integral no Brasil e no município de Goiânia (FERREIRA; REES, 2015, p. 229).

A sistematização no Gráfico 9 evidencia a distribuição do tipo de pesquisa que fundamentou o artigo por Qualis do periódico publicado.

Gráfico 9: Artigos por tipo de pesquisa e Qualis do periódico:

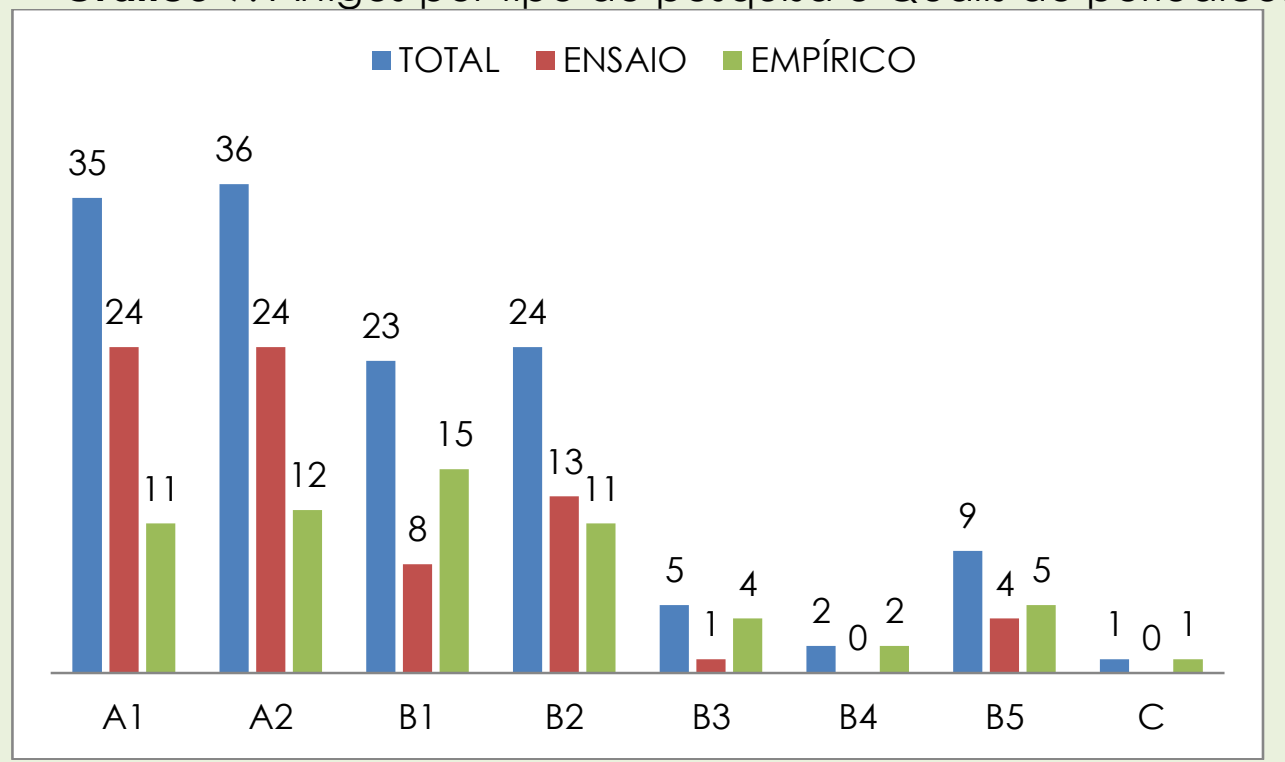

Fonte: As autoras com base no Portal Capes.

O cruzamento destas duas informações, ao que parece, manifesta que há uma tendência dos periódicos dos estratos mais elevados em privilegiar a publicação de artigos de cunho ensaístico. Do total de 35 artigos publicados nas revistas Al, no período de 2008 a 2017, 24, ou seja, 68\% eram ensaios teóricos e, dentre os 36 títulos publicados nos periódicos classificados como A2, 24, ou seja, 66\% eram de cunho ensaístico. As revistas classificadas como B1 apresentam situação inversa às revistas A1 e A2, 15 títulos (65\%) do 
total de 23 artigos divulgados traziam a empiria para o escopo do debate. Nos periódicos B2, do total de 24 artigos publicados, os artigos teóricos superam ligeiramente os empíricos, 13 (54\%) no primeiro caso e 11 (46\%) no segundo; naqueles periódicos alocados nos estratos mais baixos, os artigos empíricos prevalecem em relação aos teóricos em todos os casos.

Ao observar o cruzamento das informações sobre o tipo de pesquisa que fundamentou o artigo associado ao ano de publicação, de acordo com o Gráfico 10, vemos que até o ano de 2015 as publicações de ensaio se destacavam em relação às empíricas, cenário que se inverteu nos anos de 2016 e 2017.

Gráfico 10: Artigos por tipo de pesquisa e ano de publicação

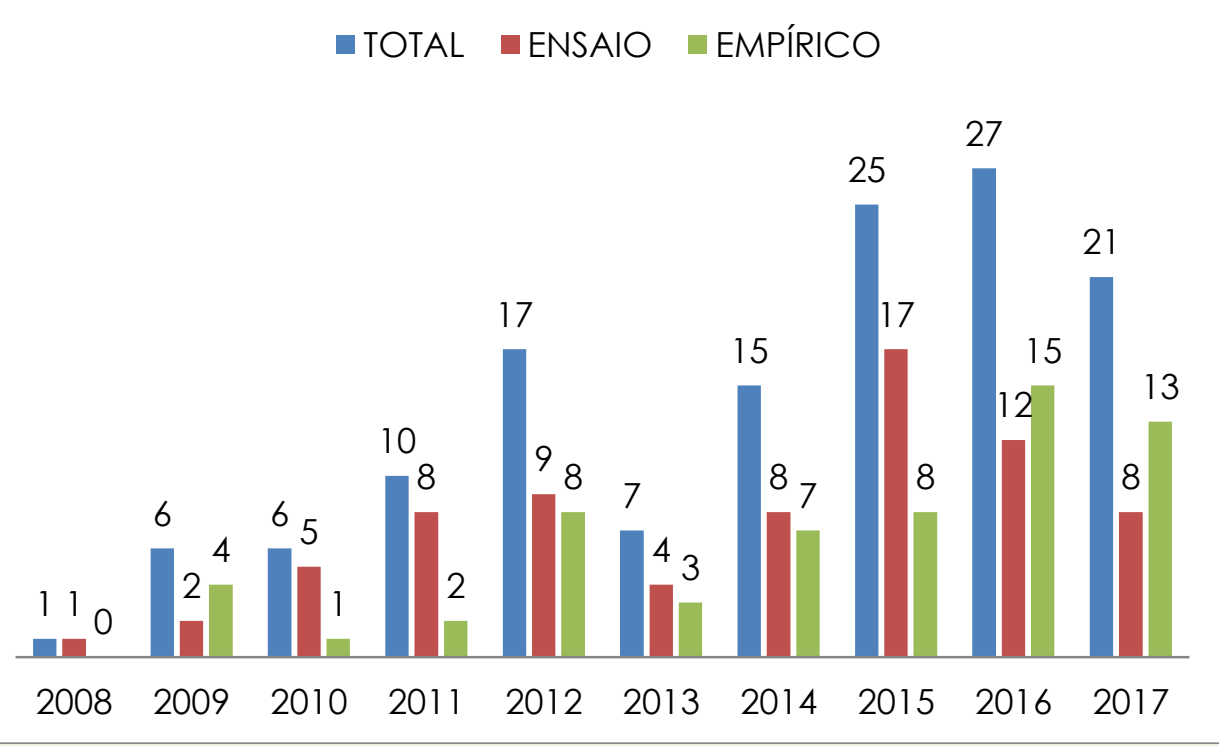

Fonte: As autoras com base no Portal Capes.

Cabe envidar esforços investigativos que possam construir explicações para esse alargamento das publicações de artigos empíricos, inclusive superando os de caráter ensaístico, nestes últimos dois anos. Entretanto, é cabível a hipótese de que a expansão das matrículas em tempo integral no ensino fundamental, conforme já registrado, tenha estimulado o interesse de pesquisadores e instituições em aprofundar a compreensão e o entendimento sobre as experiências implementadas no período. 
Os dados obtidos com a revisão bibliográfica empreendida neste estudo oportunizaram mapear como o tema da educação integral e da escola de tempo integral tem reverberado na produção de artigos científicos na última década e permitiram verificar que o tema vem se consolidando como um importante campo da pesquisa educacional.

\section{REFLEXÕES FINAIS}

Este artigo teve o objetivo de apresentar o mapeamento de artigos nos periódicos científicos sobre educação integral e escola de tempo integral que constam no Portal de Periódicos da Capes, no período de 2008 a 2017. O estudo de Ribetto e Maurício (2009), que mapeou a produção sobre o tema no período de 1984 a 2007, serviu de parâmetro para a delimitação do espaço temporal pesquisado e também inspirou a indagação que norteou esta revisão blibográfica: a ampliação das produções sobre educação integral e escola em tempo integral em artigos científicos tem permanecido na última década?

Seguramente, com base no que foi levantado e analisado, é possível afirmar que sim. O aumento das produções sobre o tema em periódicos, constatado por Ribetto e Maurício (2009) em estudo anterior compreendendo um período de 23 anos (1984 a 2007), permanece na última década, de 2008 a 2017.

Entretanto, cabe acentuar uma importante mudança em relação estudo de Ribetto e Maurício (2009) no que se refere aos recursos tecnológicos disponíveis para acesso à produção científica, especialmente artigos em periódicos. Segundo as autoras, naquela oportunidade, "foram encontrados 94 textos relativos ao tema escola de horário integral: 54 artigos em revistas acadêmicas impressas (algumas disponíveis na rede) e um em meio virtual" (RIBETTO; MAURíCIO, 2009, p. 143); já nesta revisão bibliográfica, toda a pesquisa foi efetuada por meio virtual.

O estudo permitiu, ainda, delinear alguns contornos da produção científica sobre educação integral e escola de tempo integral nos periódicos de 2008 a 2017. Os artigos abarcam uma gama extensa de circulação, os 
135 títulos levantados foram publicados em 65 diferentes periódicos. A distribuição do número de publicação por ano evidencia que, paulatinamente, vem crescendo o contingente de artigos publicados. É possível notar uma tendência à internacionalização das publicações, 09 artigos foram veiculados em revistas internacionais, pertencentes aos países: Colômbia, Costa Rica, Espanha, Estados Unidos e Portugal. A distribuição dos artigos publicados por região do periódico no Brasil revela que a região sudeste concentra maior parte das divulgações, seguida da região sul do país. É uma produção considerada de qualidade de acordo com os critérios Qualis-Capes, pois mais da metade dos artigos, 71 de 135, ou seja, 53\% foi publicada em revistas com os Qualis mais elevados, A1 ou A2.

Em relação ao tipo de pesquisa que fundamentou o artigo publicado a revisão bibliográfica apontou, com base na leitura dos resumos dos trabalhos, que pouco mais da metade do total é do tipo ensaio 74 (55\%) e os demais, 61 títulos (45\%) possuem caráter empírico. Ao que parece, há uma tendência dos periódicos dos estratos mais elevados, A1 e A2, em publicar mais artigos tipo ensaio do que empírico. De 35 artigos publicados nas revistas Al, 24 eram ensaio teórico e, dentre os 36 títulos publicados nos periódicos A2, 24 se encaixavam nesta categoria. A publicação de artigos de cunho ensaístico era maioria em relação ao tipo empírico até 2015, esse cenário se inverte nos anos seguintes, sendo maior o número de publicações de artigo tipo empírico, do que os de cunho ensaístico nos anos de 2016 e 2017.

Esta revisão bibliográfica propiciou verificar que o aumento das produções científicas em artigos sobre educação integral e escola de tempo integral tem sido permanente e progressiva desde 1984, quando Ribetto e Maurício (2009) empreenderam o primeiro levantamento sobre a temática, indicando persistente fortalecimento de pesquisas teóricas e empíricas sobre políticas de ampliação da jornada escolar. 


\section{REFERÊNCIAS}

BRASIL. MEC. Coordenação de Aperfeiçoamento de Pessoal de Nível Superior (Capes). Missão e objetivos.

http://www.periodicos.capes.gov.br/index.php?option=com_pcontent\&view =pcontent\&alias=missao-objetivos\&ltemid=102 Acesso em 23 de junho de 2018.

BRASIL. MEC. Instituto Nacional de Estudos e Pesquisas Anísio Teixeira - INEP. CENSO ESCOLAR 2016 - Notas Estatísticas. Brasília-DF. 2017.

BRASIL. Presidência da República. Plano Nacional de Educação (2014-2024). Lei 13.005, de 25 de junho de 2014.

BRASIL. MEC. Educação integral/educação integrada e(m) tempo integral: concepções e práticas na educação brasileira: mapeamento das experiências de jornada escolar ampliada no Brasil. Brasília: MEC, 2009.

BRASIL. MEC. Portaria Normativa Interministerial n- 17, Institui o Programa Mais Educação, que visa fomentar a educação integral de crianças, adolescentes e jovens, por meio do apoio a atividades sócio-educativas no contraturno escolar. Brasília, 24 de abril de 2007.

BRASIL. Presidência da República. Lei de Diretrizes e Bases da Educação Nacional: Lei n 9.394 de 20 de dezembro de 1996.

CASTRO, A. de; LOPES, R. E. A escola de tempo integral: desafios e possibilidades. Ensaio: aval. pol. públ. Educ., Rio de Janeiro, v. 19, n. 71, abr./jun. 2011.

CAVAlIERE, A. M., Anísio Teixeira e a educação integral. Paidéia, vol. 20, n. 46, maio-ago. 2010.

FARIA, L. CIEP: a utopia possível. São Paulo: Livros do Tatu, 1991.

FELÍCIO, H. M. S. A instituição formal e a não-formal na construção do currículo de uma escola de tempo integral. Educação em Revista, Belo Horizonte, v.27, n.03, dez. 2011.

FERREIRA, H. B.; REES, D. K. Educação integral e Escola de tempo integral em Goiânia. Educação \& Realidade, Porto Alegre, v. 40, n.1, P. 229-251, jan./mar.2015.

FERREIRA, N. B. P.; DUARTE, N. As artes na educação integral: uma apreciação histórico-crítica. Revista Ibero-Americana de Estudos em Educação, v.6, n.3, 2011. 
FERREIRA, N. S. A. As pesquisas denominadas "estado da arte". Educação \& Sociedade, Campinas, SP, v. 23, n. 79, 2002.

GADOTTI, M. Educação integral no Brasil: inovações em processo. São Paulo: Instituto Paulo Freire, 2009.

HAYASHI, M. I.; KERBAUY, M. T. M. A Educação Integral na produção acadêmica de teses e dissertações (2010-2015). Revista Ibero-Americana de Estudos em Educação, v.11 (2), p.836-855, 2016.

MEIRELLES, R. F.; MACHADO, R. N. Y. A funcionalidade e o desempenho do Portal de Periódicos da CAPES entre pesquisadores das áreas de Comunicação e Ciência da Informação da Univerisdade Federal da Bahia. Perspectivas em Ciência da Informação, v. 12, n. 03, p. 54-64, set/dez 2007.

MESSINA, G. Estudio sobre el estado da arte de la investigacion acerca de la formación docente en los noventa. Organización de Estados

IberoAmericanos para La Educación, La Ciência y La Cultura. In: Reúnion de consulta técnica sobre investigación en formácion del professorado. México, 1998.

MOLL, J.; LECLERC, J. Diversidade e tempo integral: a garantia dos direitos sociais. Revista Retratos da Escola, Brasília, v.7, n.13, p. 291-304, jul./dez. 2013.

MOROSINI, M. C. Estado de conhecimento e questões do campo científico. Educação, Santa Maria, v. 40, n. 1, p. 101-116, jan./abr. 2015.

PUENTES, R. V.; AQUINO, O. F.; FAQUIN, J. P. S. Estado del Arte sobre Formación de Profesores en América Latina: significado, orígenes y fundamentos teórico-metodológicos. Revista Digital UMBRAL, [S. I.], n. 17, 2005.

RIBETTO, A.; MAURÍCIO, L. V. Duas décadas de educação em tempo integral: dissertações, teses, artigos e capítulos de livros. Revista Em Aberto, v. 22, n. 80, p. 137-160, abr. 2009.

ROMANOWSKI, J. P.; ENS, R. T. As pesquisas denominadas do tipo "estado da arte" em educação. Diálogo Educacional, Curitiba, v. 6, n.19, p.37-50, set./dez. 2006.

SEVERINO, A. J., Metodologia do trabalho científico. S.P.:Cortez, 1996.

SILVEIRA, J. P. B. A produção científica em periódicos institucionais: um estudo da revista biblos. Enc. Bibli: R. Eletr. Bib. Ci. Inf., Florianópolis, v. 17, n. 33, jan./abr., 2012. 
RAMOS, M. Y. Internacionalização da pós-graduação no Brasil: lógica e mecanismos. Educ. Pesqui., São Paulo, v. 44, 2018.

SILVA, J. A. A.; SILVA, K. N. P. A hegemonia às avessas no Programa Mais Educação. Rev. bras. Estud. pedagog. (online ), Brasilia, v. 94, n. 238, set./dez. 2013.

SILVA, M. C. G. A educação integral na escola de tempo integral: as condições históricas, os pressupostos filosóficos e a construção social da política de Educação Integral como direito no Brasil. Tese de Doutorado. Faculdade de Educação - UNICAMP, Campinas, 2018. 146 f.

SOARES, M. B.; MACIEL, F. Alfabetização. Brasília: MEC / INEP / COMPED, 2000. TEIXEIRA, A. Uma experiência de Educação Primária Integral no Brasil. Revista Brasileira de Estudos Pedagógicos, Rio de Janeiro, vol. 38, n 87, p. 21-33, jul./set., 1962.

Recebido em: Janeiro de 2018 Aprovado em: Maio de 2018 